\title{
Vaccines, pandemic politics, and the global south
}

In describing the pandemic, the UN Secretary General Antonio Guterres stated in April 2020 "we are all in it together". This commendable statement tried to drive home the point that the COVID-19 pandemic is a common challenge for the entire humankind, and that a well-coordinated unified effort is needed from the world community - whether from the global north or south, majority or minority, infected or uninfected, to counter this unfolding human crisis. The twists and turns in the pandemic over the past one and a half years clearly demonstrated that everyone was vulnerable from the heads of state at the top to mobile vendors on the streets. It also showed that while the virus does not discriminate, its impact does with elderly in institutional care, ethnic and racial minorities and socially underprivileged in general among the worst victims of the early phase of the pandemic globally. How the world will emerge from this terrible crisis is yet to be seen, but whether we like it or not it has taught us many lessons about what we should do and not do in responding to a global pandemic of this magnitude and the accompanying humanitarian crisis.

The powerful unifying statement by the Head of UN was made at a time when the pandemic was polarizing the world community in some fundamental ways. One was the disproportionate number of people of colour and minorities in general who fell victim to the pandemic in the United States and certain countries in Europe particularly during the onset of the pandemic. Thus, the pandemic was exposing serious disparities and the absence of universal coverage in the health care system even in the most economically advanced countries. Another issue was the pandemic of hate triggered by COVID-19 outbreak, reflected in some mainstream and social media, whereby ethnic and religious other was often identified and labelled as the vector or carrier of the virus, reportedly spreading it to others at times deliberately. Thus, the social and political polarizing impact of the pandemic was as bad as its health (i.e., morbidity and mortality) impacts. We have seen some manifestations of this polarizing social impact of the pandemic in Sri Lanka as well. It is against this background that this valiant call for global unity and solidarity at the time of the pandemic must be appreciated. It is not framed as a plea for an unanticipated surge in 'love in the time of corona' along the lines of the award-winning novel of Marquez. Rather it was a pragmatic call for forgetting and perhaps overcoming the escalating internal differences within the world community when confronted by an unprecedented public health emergency unfolding right before our eyes.

Like many other UN calls and declarations, this enlightened UN statement too has fallen by the wayside. 'Vaccine nationalism' of developed countries directly relevant in the present context of the pandemic is a case in point. For vaccines to be effective as a widespread public health strategy for the control of COVID-19, the entire world inclusive of developing countries must have reasonable access to the vaccines so that the virus is contained satisfactorily throughout the world. However, the developed countries that manufacture the vaccines and have the technology and resources needed for production of vaccines have decided to order, stockpile and hoard much more than they actually require, purely taking their own self-interest into account to the neglect of the third world countries, in particular. According to an article published in the Guardian in March 2021, the world's rich countries with a total share of $14 \%$ of the 
global population, have secured $53 \%$ of the best vaccines for COVID-19 produced or planned to be produced at the time (Bhutto, 2021).

On the other hand, many countries in the global south will encounter a formidable challenge in importation of life-saving vaccines at current market prices due to their budgetary constraints and foreign exchange problems. This is likely to be even more challenging for smaller countries in the global south like Sri Lanka which are already heavily entangled in a debt trap along with intractable debt servicing problems as elaborated by Vinayagathasan and Sri Ranjith in their article in this issue of Sri Lanka Journal of Social Sciences (SLJSS). This situation is likely to create space for the virus to freely replicate and mutate in part of the world population in ways that will make it harder to contain the pandemic globally and prevent its upsurge in future. The reactions of corporate giants in the pharmaceutical world against cheaper manufacture of vaccines in the developing world reiterate the point that profits rather than human health across the board is the key driver of the global pharmaceutical industry. The fact that virus strains that emerged in India have spread to over 40 countries within a short period of their origin clearly points to the massive danger involved (Shrivastava, 2021). China may be guided by their own vested interests and geopolitical agendas in rapidly developing and liberally distributing their own vaccines, but the truth is that without access to lubricated and fast track Chinese supply line much of the developing world will be at the mercy of the multinational pharmaceutical corporations who will only use the pandemic as another profitable venture for accumulating wealth.

This is, however, not to argue that we should counter vaccine nationalism of the developed world with our own brand of home-grown parochial nationalism where we limit ourselves to herbal remedies inherited from the past or so-called miracle sweeteners (paniya) of one kind or another. Instead, what is needed is a critical approach where we subject both scientific inventions and herbal therapies and inherited legacies to equally robust validation procedures without accepting them uncritically just because they are sanctioned and legitimized by western science or "power of ancient knowledge" (Perera, 2021) combined with eastern mysticism at times driven by populist identity politics and deep-seated political instincts. At this critical juncture of pandemic politics, we need to work towards evolving social policies and decision-making processes that are well informed, evidence based and able to withstand intense competition for limited resources, political pressures and partisan demands for favouritism in matters such as vaccination coverage. While the pandemic does call for urgent action, monitoring and evaluation should be part and parcel of all interventions for pandemic control and mitigation just as much as they are routinely deployed in all development practice. What is important at this stage is a carefully crafted state policy that transcends narrow fault lines in society and polity and seeks to stand for collective interests and the common good of all humanity confronted by an unprecedented common challenge with all of us entangled in it collectively. This is where countries in the global north as well as global south must transcend short-term self-interests and popular appeal to identity politics in order to face an unprecedented global challenge where we are all entangled in one way or another.

Papers in this issue of SLJSS are diverse as they deal with a variety of economic, social and cultural issues. None of the papers in this issue speak to the devastating pandemic immediately confronting us as a society. They do, however, highlight the need for well-informed social policies in selected domains in life. For instance, Perera's article on social safeguard policies of the World Bank, Asian Development Bank and other such agencies reveal that while such policies have been carefully developed and imposed by these multilateral banks on their borrowers, they are not well integrated with related policies and principals of other international players such as the United Nations. The article has a specific focus on their lack of integration with Universal Declaration of Human Rights. The article also comments on the lack of fit between the social safeguard principles advocated by these lending institutions and ground level realities of developing countries, with the lenders having to "nudge the borrowers to adopt safeguard best practices" (this issue: p. 07) without necessarily pushing them to incorporate the guidelines in their development practices in general. The author reiterates the point that social safeguard policies of these key development actors are guided by the immediate concerns of the lending institutions and their global agendas rather than changing ground realities and economic and social drivers in the developing world itself.

Another interesting analysis about social policy is presented by Wanninayake in his paper in the current issue of SLJSS. In contrast to much of the literature dealing with the larger body of Tamil and Muslim IDPs in northern and Eastern Sri Lanka, this article focuses on Sinhala IDPs displaced from Vavuniya South to northern part of Anuradhapura District during the war. The prevailing state policies encouraged war induced IDPs to go back to where they were displaced from at the end of the war. Most of the IDPs in Anuradhapura, however, opted to stay back in Anuradhapura using existing and newly established kinship ties to establish 
a self-settlement pattern and a wide range of social networks with host communities (p. 84). The prevailing state policies about return and resettlement of IDPs which tried to re-establish the status quo prior to their displacement perhaps due to ideological and political reasons were obviously uninformed by this sociological reality that the author identifies as a successful adaptation mutually beneficial to both IDPs and their hosts due to economic and social considerations applicable to the post war situation. IDPs did contribute to economic development in host areas by sharing their agricultural knowledge and skills, disseminating cultivation methods and supplying farm labour at a time when many local youth were mobilized in military employment. The paper calls for a IDP resettlement policy that is more in line with ongoing social reality and choices made by the IDPs themselves in place of armchair policy making by bureaucrats and politicians purely guided by political exigencies and ideological considerations of the ruling regime at the time.

The UN policy stand regarding the pandemic has an immediate relevance to us as there is a distinct need to reach out to all sections of society and make them realise that we are all in it together and that we must work together diligently and intelligently in dealing with the pandemic. While enforcement of quarantine regulations and health guidelines is certainly needed, people must realise that their health is partly in their own hands, but partly in the hands of the community at large and at the hands of a heartless virus adept at multiplying that can be contained only collectively. In tracing the global history of epidemics, McNeill (1976) observed "Humans often have complicated and contradictory motivations. Microbes do not: they 'want' to reproduce." Trust building in systems and among each other is as much needed as delivering vaccines and establishing effective health services and effective hand washing practices in workplaces at this hour of national and global emergency. It must be stated here that Sri Lanka's outstanding achievements in public health developed from 1930s onwards ultimately rest in the skills, dedicated commitment, and application of health workers at all levels and the confidence with which the public voluntarily utilized the services available as a routine practice. As an unfolding global event, a pandemic may be a completely different challenge, but we have dealt with similar epidemics in the past and we have a well-developed health care system with wide outreach to all communities in the country (Jones, 2015; Silva, 2014). All efforts must be made to reinforce and revitalize this system in dealing with the crisis at hand.

\section{REFERENCES}

Bhutto, F. (2021) The World's Richest Countries are Hoarding Vaccines, The Guardian [Online] March 17, Available from: https://www.theguardian.com/commentisfree/2021/mar/17/ rich-countries-hoarding-vaccines-us-eu-africa [Accessed: $15^{\text {th }}$ May 2021].

Jones, M. (2015) Sri Lankan Path to Health for All from the Colonial Period to Alma Ata, In A. Medcalf et al. (eds.) Health for All: The Journey of Universal Health Coverage, Hyderabad: Blackswan.

McNeill, W. (1976) Plagues and Peoples, Garden City: Doubleday.

Perera, S. (2021) Science, Belief and State Policy: Towards a Necessary Exercise in Discursive Disentanglement, 22 January, Presentation at Induction Ceremony of New Fellows of the National Academy of Sciences, Sri Lanka [Online] Available from: https://nassl.org/nassl-induction-ceremony-2020/ [Accessed: 18 ${ }^{\text {th }}$ May 2021].

Silva, K. T. (2014) Decolonisation, Development and Disease: A Social History of Malaria in Sri Lanka, Delhi: Orient Blackswan.

Shrivastava, B. (2021) Virsu Strain behind India's Surge in Covid Cases Detected in 44 Countries, Fortune, May 12, 2021.

Kalinga Tudor Silva 